\title{
The woman and the penile prosthetic implant. Primary or secondary role? Personal experiences on 355 implanted patients
}

\author{
Diego Pozza ${ }^{1}$, Alberto Berardi ${ }^{2}$, Mariangela Pozza ${ }^{1}$, Augusto Mosca ${ }^{2}$, Carlotta Pozza ${ }^{3}$ \\ ${ }^{1}$ Studio di Andrologia e di Chirurgia Andrologica, Rome, Italy; \\ ${ }^{2}$ U.O. Urologia, S. Sebastiano Hospital, Frascati, Italy; \\ ${ }^{3}$ Department of FPM, Sapienza University, Rome, Italy.
}

\begin{abstract}
Summary Objective: We evaluated the role of women (wife, partner, girlfriend, lover) in the decision and the results of Penile Prostheses Implants (PPI). Material and methods: In a group of 355 pts (21-82 years, average age 50.3 years) submitted to PPI since 2007, we recorded data concerning the relationships with their partner and their role in the surgical decision. We implanted 97 Semirigid (SPP), 136 Malleable (MPP) and 122 Inflatable (IPP) Prostheses. We collected data regarding some aspects of the sexual life of patients. We asked them if they were married, divorced or widowed; if they had a lover; if they go regularly to brothels; if they were satisfied of their actual couple's life. After surgery we recorded data concerning their difficulties in utilizing the PPI and their level of satisfaction.

Results: Most patients (93\%) confirmed their satisfaction after PPI. Relational aspects: 44 out of 46 unmarried patients with difficult sexual intercourses managed to have regular sex and decided to marry after PPI, including 5 younger patients (2130 years old) who were not able to penetrate their girlfriends. In the group of married patients 5 pts were not able to penetrate their wives; after PPI they managed to have regular intercourses and pregnancies.

Fifteen widowers and 22 divorced patients decided to have a PPI for possible sexual dating or stable relationships.

Ninety-six out of 271 (28.2\%) married patients declared a stable extramarital relationship that represented the main reason for having a PPI.

Conclusions: In our opinion the simple act of penetrate and ejaculate in vagina, without considering the importance of personal, relational, emotional factors, often well linked to a specific woman, cannot be considered the ideal target of PPI.
\end{abstract}

KEY WORDS: Penile prosthesis; Penile prosthesis implant; Psychosexual factors; Couple.

Submitted 22 September 2020; Accepted 22 November 2020

\section{INTRODUCTION}

Penile Prostheses Implants (PPI) have been considered as one of the ultimate treatments of Erectile Dysfunction (ED) since $1972(1,2)$. In most cases, evaluation of the patients to be submitted to PPI included various parameters such as age, race, metabolic and general diseases, hormonal conditions, cardiovascular diseases, tobacco smoking, alcohol, drugs. The role of women (wife, partner, girl- friend, lover) is rarely evaluated while, in our opinion, the ongoing relationship with the woman is crucial when the male must make the decision to undergo surgery to solve his ED (3). In our experience, patients with ED try to find a solution (psychotherapy, drugs, hormones, 5PDEi, PGEl, urethral alprostadil, low intensity extracorporeal shockwave therapy, penile implants) not only to manage to have an erection but, mainly, if not exclusively, to have the opportunity to have sex with their partners. If a male does not have sexual intercourses for religious choices, personal principles, lack of interest, limits of freedom, geographical factors (deportations, emigration, work shifts) probably he is not particularly bothered by his ED. If the male feels the need to have an orgasm and ejaculation, he can obtain it with masturbation, possible even with a not fully erect penis. Many men over 50, of medium-high cultural level, with good profession, high work responsibilities, good income, one or more children, have no particular interest in having sex with their wives after 10-15 years of marriage (4-5) or even with a lover often because afraid of not being able to perform. Until 30-40 years ago, males could have regular sex only after marriage; in married couples usually the male took the initiative and the woman had little chance of refusing. Often, after giving birth to several children and as they became older, women might show a decline in sexual desire and, as menopause approached, the willingness to have sex might become less frequent and rewarding (6), due to the fatigue to take care of several children and the family and the lack of enough amusements and distractions. If a male complains ED and is less inclined to have sex, this doesn't represent a problem for the wife and for the couple.

A great number of patients, over 35 years of age, visiting our Center, states that they have sexual intercourses with their wives, generally, every 7-10 days; the frequency of sexual intercourses with the lovers is the same. For the couple, generally, the working time and the travel back home is tiring; they have to check if the children did their "job" and spend time with them; after dinner they watch TV or prepare for the next day and generally, they go to sleep after 11-12 p.m. and are very tired; they have to wake up early next morning. Generally, there isn't enough time for sex. Things are different in the weekend or during holidays when the frequency of sexual intercourses

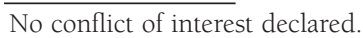


increases significantly. Another factor influencing the frequency of marital intercourses, in the last 10-20 years, is represented by the sex-web with an increase of web-masturbation (7). Many men report web-masturbation several times a week. After masturbation, males have no feeling or strength to have a sexual intercourse with their wives. Today, most patients ( $>40$ years old) who visit our center for andrological problems generally refer sexual intercourses only in the weekend.

The DE is no longer a drama, but something missing that becomes important only if a male begins an affair or wants children and would like to increase the frequency of sexual intercourses. Often only in these circumstances a male seeks an ultimate solution of his ED. For about 20 years we have been evaluating the relationships of our patients requiring a prosthetic solution for their ED.

We started to consider the reactions of the partners; if they were informed of the surgical decision and if they supported or refused such a solution (8).

In cases of married patients, we consider if they had extramarital relationships or if they buy prostitutes.

In case of divorced or widowed patients, we investigated if the patients would prefer to remain alone in the future or if, instead, they would desire a new relationship both for domestic partnership and sexual activity.

\section{MATERIALS AND METHODS}

Since 1984 more than 39.000 patients presented to our private Studio di Andrologia for erectile or ejaculatory dysfunctions (about 40\%), infertility (40\%) and/or urologic problems (15\%) (9). After diagnosis, specific therapies have been suggested.

For patients affected by ED (a group of 9.200 pts) after the visit and specific diagnostic examinations (metabolic analyses, hormonal evaluations, often Nocturnal Penile Tumescence test with Rigiscan, dynamic penile duplex sonography, magnetic resonance imaging, neurological and cardiological examinations), we prescribed the available therapeutic modalities (psychotherapy, drugs, vasodilators, venous surgery, $5 \mathrm{PDEi}$, vasoactive injections, Medical Urethral System for Erection or MUSE, urethral alprostadil creams, Low Intensity Extracorporeal Shockwave Therapy or LIESWT).

We suggested the penile prosthetic solution to $750 \mathrm{pts}$ who didn't report any satisfactory results. Out of them 577 accepted such option for treating their ED.

In the first period (1984-2006) we recorded in our files only if the male was married or not. Since 2007 (i.e. for the last 355 pts) we are recording more complete information dividing the patients in 6 groups:

1. Single patients without no relationship and no sexual intercourses with women;

2. Single patients with the opportunity to have sexual intercourses;

3. Married patients with regular sexual activity;

4. Married patients with wives who avoided or refused sexual intercourses;

5. Married patients with sexual intercourses outside the marriage, with fixed relationships, lovers or prostitutes;

6. Divorced or widowed patients who would like to start stable relationships for the future.
We did not use validated and dedicated questionnaires about QoL. The fact that medical visits had to be paid for limited the number of patients who mainly belonged to the middle or high class. Normally, we did not use to send patients to a psychologist before surgery.

Patients were affected by various pathologies as venous or arterial and mixed vascular diseases; diabetes type 2; hypertension; Peyronie's disease; prostate and pelvic surgery outcomes; psychological and relational problems. We implanted a wide variety of PPI [Semirigid, Silicone: 97 (SPP); Malleable: 136 (MPP); Inflatable: 122 (IPP)]. This was always justified by the search for low-cost PPI, because in Italy patients had to pay for the Clinic, Prosthesis and Surgeons. As a rule, we visited patients 7 10 days post-op and after about 1 and 12 months.

A group of 36 pts did not comply to follow-up. Many patients continued to carry out periodic and regular checks for many years afterwards.

\section{Results}

Results of PPI can be considered satisfying $(1,9)$ even if we recorded complications related to infections (14 pts, $3.9 \%$ ) or malfunction of prosthetic cylinders and inflatable system (18 pts, 5.0\%). In general, the patients who chose prosthetic surgery because they had ineffective sexual relationship, were able to have full sexual intercourses, although a share of them (15\%) complained a shortening of the rod, a difficult penetration with semirigid and malleable prostheses (possible bending) and a significant loss of skin sensitivity.

\section{Unmarried}

Forty-four out of 46 unmarried patients with difficult sexual intercourses managed to have regular sex and decided to marry after PPI, including 5 younger patients (21-30 years old) who were not able to penetrate their girlfriends. Only two patients continued to avoid sexual relationships for performance anxiety or for the lack of a stable partner.

\section{Married}

All the married patients after PPI were able to have sexual intercourses, except three patients who reported a strong rejection by their wives who refused any kind of sexual intercourse. Five patients who were never able to have penetrative intercourses after marriage managed to have a full and satisfying sexual life after PPI.

We did not test the index of appraisal of the women (10) after their husbands' PPI (11).

\section{Extramarital relationships, divorced, widowed}

All pts who had a lover, referred good and improving sexual relationships.

All divorced and widowed males who decided to have the PPI for a possible and new familial and sexual relationship referred to be fully satisfied of the PPI.

Obviously in this group of patients we were not able to analyze the reactions of their partners.

\section{Psychological difficulties after IPP}

Many males, after PPI, were often blocked by the fear that a new partner might notice the presence of the cav- 
Table 1.

Sexual activity and relationships of patients before surgery by age group.

\begin{tabular}{|c|c|c|c|c|c|c|c|}
\hline \multirow{2}{*}{$\begin{array}{l}\text { Patients } \\
\text { Years }\end{array}$} & \multirow[b]{2}{*}{ No. } & \multicolumn{2}{|c|}{ GirlFriends } & \multirow{2}{*}{$\begin{array}{l}\text { Marriage } \\
\text { coexistence }\end{array}$} & \multirow{2}{*}{$\begin{array}{c}\text { Extramarital } \\
\text { affairs }\end{array}$} & \multirow[t]{2}{*}{ Divorced } & \multirow[t]{2}{*}{ Widow } \\
\hline & & Never had sex & Sex difficulties & & & & \\
\hline$<21$ & 6 & 3 & 3 & 0 & 0 & 0 & 0 \\
\hline $21-30$ & 30 & 3 & 22 & 5 & 2 & 0 & 0 \\
\hline $31-40$ & 44 & 2 & 13 & 28 & 3 & 0 & 0 \\
\hline $41-50$ & 75 & 0 & 0 & 69 & 23 & 5 & 1 \\
\hline $51-60$ & 98 & 0 & 0 & 92 & 34 & 4 & 2 \\
\hline $61-70$ & 64 & 0 & 0 & 54 & 26 & 6 & 4 \\
\hline $71-80$ & 33 & 0 & 0 & 22 & 8 & 5 & 6 \\
\hline $81-90$ & 5 & 0 & 0 & 1 & 3 & 2 & 2 \\
\hline Total & 355 & 8 & 38 & 271 & 96 & 22 & 15 \\
\hline
\end{tabular}

Table 2.

Protheses implanted in 355 patients.

\begin{tabular}{|lcccc|}
\hline Patients & \multicolumn{5}{c|}{ Penile prostheses } \\
\hline Years & Semirigid & Malleable & Inflatable & Total \\
\hline$<21$ & 6 & 0 & 0 & 6 \\
\hline $21-30$ & 18 & 6 & 6 & 30 \\
\hline $31-40$ & 16 & 18 & 10 & 44 \\
\hline $41-50$ & 17 & 34 & 24 & 75 \\
\hline $51-60$ & 20 & 38 & 38 & 96 \\
\hline $61-70$ & 14 & 18 & 32 & 64 \\
\hline $71-80$ & 5 & 20 & 10 & 35 \\
\hline $81-90$ & 1 & 2 & 2 & 5 \\
\hline 51.20 mean & 97 total & 136 & 122 & 355 \\
\hline
\end{tabular}

ernous cylinders both semi-rigid and inflatable. In our experience, at least 5 patients with severe erectile dysfunction preventing sexual relationships, after the prosthetic implant admitted great difficulties in the first intercourses, because afraid of being discovered by their partner.

Most of our patients with MPP implants referred a better acceptance by their partners, because the penetration was easy after usual foreplay without particulars manoeuvres.

Patients with IPP could get better erection but they have to obtain it by inflating the IPP. A limited number of wives complained that the foreplay was compromised by these manoeuvres to have an artificial erection, thus changing the feeling about it. Three out of 110 partners of patients with IPP (2.7\%) considered this a reason for rejecting sexual intercourses with their husbands (12 were lost at follow up). On the contrary, 220 out of 223 patients with SPP/MPP never referred that this was relevant (10 lost at follow up).

In general, patients with partners who accepted or had been favourable to prosthetic surgery were able to use the prostheses earlier and with greater frequency of intercourses and satisfaction.

This confirms the importance of the involvement and collaboration of the partner in the decision, preparation and post-op course of PPS (12).

In our clinical experience, 15 patients already personally convinced and just included in the program for penile prostheses implantation gave up or had to give up surgery due to the firm opposition of their no longer young wives, who considered the decision of their partner not absolutely relevant to modify or improve their relationship, that they considered optimal even if with scarce or no sexual activity.

\section{Discussion}

The PPI is an effective option to treat ED especially in patients where pharmacological solutions have not provided satisfactory results.

Questionnaires, such as the Female Sexual Function Index (FSFI) $(10,13,14)$, reporting the opinion of women on sexual function of their husbands or partners, are important to evaluate their sexual function and quality of life after PPI $(15,16)$.

In the past, the Literature addressed women sexual satisfaction in a generic way when reporting the satisfaction shown by women in relation to the penile prostheses of their partners.

Another problem begins to be observed in women with sexual dysfunction already existing before the resolution of the erectile dysfunction of their partners, who got used to the ED of their partners and after PPI begin to develop a high level of stress, as a result of the new requests and expectations made possible by the penile prosthetic implant (17). It has sometimes emerged that the wife, no longer young, begins to fear that the husband may be interested and involved in extramarital relationships, not possible as long as an ED was present. In those cases, it is important for the man to express his intention to integrate PPI into the sexual life of the couple. The man must make his wife understand, that the decision to have a PPI is aimed at restoring a correct sexuality in the couple. If this does not happen, it is probably too late to make that decision.

The partner's decision should be understood and respected. Obviously, it is essential to evaluate the sexual life of a couple before the decision to have a PPI implanted, because a woman who has not been having sexual intercourses for a long time, due to her husband's $\mathrm{ED}$, or had a decrease in desire, might not be cooperative and participate in her partner's decision. It is often the surgeon's clinical ability and sensibility to illustrate the positive effects of PPI in the couple's life. Until not long ago, the sexual life of menopausal women was culturally stigmatized. Today, with the advent of hormonal therapies and the challenging and often rewarding social role, this perception has changed, and active desire and sexual life are universally accepted even at this stage of life. PPI is often considered as an "inconvenient third" in the intimacy of the couple even if it makes significant changes in the sexual health of the couple itself. In the Literature, the importance of the women role in the treatment of patients is not taken into account. This can affect the overall vision about the surgery itself. In an Italian Survey (18) it was reported that about half of the sample (50.7\% of men and $48.4 \%$ of women) was eager to choose (men) or to support (women) the choice of PPI in case of severe ED and the majority of both sexes (71.3\% of males and $76.3 \%$ of females) did not oppose to the 
choice of PPI. Generally, the surgeon is not properly prepared, if not for personal factors and sensibility, to deal with the dynamics of the couple and, as a result, he/she often prefers not to involve the partner and to discuss all aspects only with the patient. Adjusting false expectations and addressing the patient's doubts and concerns implies a willingness to dialogue and the involvement of various specialists, which is almost never possible. It would be important, after surgery, to join in sexological counselling sessions to help the couple regain the intimacy they lost after the ED and to recover after PPI. The recent Clinical Recommendations of the European Society for Sexual Medicine points out that at present there are no standardized methods to determine the male and his partner expectations (19). Careful and scrupulous sexological counselling seems to be fundamental to prevent the negative aspects of PPI on the couple relationship. Even in these situations, the role of women is important in supporting the expectations of their partners and in driving the approach to consider having sex as a moment of intense couple relationship.

\section{Conclusions}

In most cases, people tend to consider the penile prosthesis as a significant change in the man's or couple's life. For this change to be actually positive, it should promote the reinstatement of the psychosexual well-being of the patient and the couple. The clinician should take into account the necessary integration between surgical therapy and psychosexual counselling in the path leading to penile prosthesis. PPI can in fact allow penetrative intercourses and reduce the patient's discomfort in his sexual life in general, but at the same time, due to the irreversibility of prosthetic choice, it could trigger personal and couple dynamics related to the loss of sexual freedom and spontaneity. It would therefore be appropriate to involve, after the patient's first visit, the current partner who could provide important elements in the diagnostic phase and, therefore, help to reinforce the choice of the best therapeutic solution. In the case of PPI in particular, the involvement of women, who can be informed about the technical aspects of PPI and actually support their partners, could reduce the possibility of postoperative psychosexual complications. In addition, an indepth knowledge of the couple and their sexuality could allow a better monitoring of the subsequent results. In such cases, it is important for the partner to express her concerns considering the possibility of integrating the prosthesis into the couple's sexual life. The man must be able to reassure his partner that the decision to undergo surgery is something aimed at recovering the couple sexuality. If that does not happen, maybe it's a little late to make such an important decision. This article aims at emphasizing how important it can be to consider the impact of such an important "surgical solution" as a PPI, not only as a simple procedure but also as a factor with psychosexual consequences on the life of the man but also on the one of his partners. Careful evaluation and psychosexual counselling are essential to prevent negative effects on the couple's life. In most cases the role of women is important, both to support the expectations of their partners and to adapt to the feasibility for sexual intercourses when the sexual life as a couple is not particularly intense. Based on our over-35-year experience, we consider it important to be able to involve women from the very first steps, i.e. from the diagnosis and therapy phase of their partner's ED to the decision to undergo a PPI. Women can help their partners to take this delicate and complex surgical decision, in order to find a new functional reality of the couple and be able to share the benefits and possible difficulties related to PPS.

\section{Aknowledgements}

We thank Dr Roberta Rossi, PhD, Istituto di Sessuologia Clinica of Rome for the invaluable advices and comments to the preparation of the article.

\section{REFERENCES}

1. Wilson SK, Delk JR. Historical advances in penile prostheses. Int J Imp Res. 2000; 12:101-7.

2. Chevallier D, Faix A, Bettocchi C, et al. Penile prosthesis in the treatment of erectile dysfunction: updates in 2020.Rev Med Suisse. 2020; 16:525-30.

3. Vakalopoulos I, Kampantais S, Ioannidis S, et al. High patient satisfaction after inflatable penile prostheses implantation correlates with female partner satisfaction. J Sex Med. 2013; 10:2774-81.

4. Carter A, Ford JV, Luetke M, et al. "Fulfilling his needs, not mine": reasons for not talking about painful sex and association with lack of pleasure in a national representative sample of women in the United States. J Sex Med. 2016; 16:1953-61.

5. Beutel ME, Burghardt J, Tibubos AN, et al. Declining sexual activity and desire in men-findings from representative German surveys 2005 and 2016. J Sex Med. 2018; 15:750-6.

6. Simonelli C, Eleuteri S, Petruccelli F, et al. Female sexual pain disorders: dyspareunia and vaginismus. Curr Opin Psychiatry. 2014; 27:406-12.

7. Duffy A, Dawson DL, Das Nair R. Pornography addiction in adults: a systematic review of definitions and reported impact. J Sex Med. 2016; 13:760-77.

8.Barton GJ, Carlos EC, Lentz AC. Sexual quality of life and satisfaction with penile prostheses. Sex Med Rev. 2019; 7:178-88.

9. Pozza D, Pozza M, Musy M, et al. 500 penile prostheses implanted by a surgeon in Italy in the last 30 years. Arch Ital Urol Andr. 2015; 87:216-23.

10. Rosen R, Brown C, Heiman J, et al. The Female Sexual Function Index (FSFI): a multidimensional self-report instrument for the assessment of female sexual function. J Sex Marital Ther. 2000; 26:191-208.

11. Rosen RC, Riley A, Wagner G, et al. The International Index of Erectile Function (IIEF): a multidimensional scale for assessment of erectile dysfunction. Urology. 1997; 49:822-30.

12. Özbay E, Aydın A, Salar Rm, et al. Sexual experiences between partners after penile prosthesis: Who is more satisfied? Andrologia. 2020; 52:13461-6.

13. Awwad AA, AboSeif AF, Fattag Farag MA, et al. Sexual functions of females married to males with semi-rigid penile Implants: a cross-sectional study. Urologia. 2019; 86:197-201. 
14. Isidori AM, Pozza C, Esposito K, et al. Development and validation of a 6-item version of the Female Sexual Function Index (FSFI) as a diagnostic tool for female sexual dysfunction. J Sex Med. 2010; 7:1139-46.

15. Gittens P, Moskovic JD, Desiderio Avila Jr, et al. Favorable female sexual function is associated with patient satisfaction after inflatable penile prosthesis Implantation. J Sex Med. 2011; 8:19962001.

16. Portman DJ, Gass MLS. Genitourinary syndrome of menopause: new terminology for vulvo vaginal atrophy from the international society for the study of women's sexual Health and the North American Menopause Societ. J Sex Med. 2014; 11:2065-72.

17. Omonov D, Christopher AN, Blecher GA. et al. Clinical
Recommendations from the European Society for Sexual Medicine exploring partner expectations, satisfaction in male and phalloplasty cohorts, the impact of penile length, girth and implant type, reservoir placement, and the influence of comorbidities and social circumstances. J Sex Med. 2020; 17:210-37.

18. Pescatori ES, Baldini A, Parazzini F, et al. How much do people know about male sexual problems? A survey in a selected population sample. Arch Ital Urol Androl. 2019; 91:182-6.

19. Caraceni E, Utizi L. A questionnaire for the evaluation of quality of life after penile prosthesis implant: quality of life and sexuality with penile prosthesis ( $(\mathrm{LLSPP})$ : to what extent does the implant affect the patient's life? J Sex Med. 2014; 11:1005-12.

\section{Correspondence}

Diego Pozza, MD (Corresponding Author)

diegpo@tin.it

Mariangela Pozza, MD

mariangela.pozza@gmail.com

Carlotta Pozza, MD, PhD

carlotta.pozza@gmail.com

via B. Gozzoli, 82C, 00142 Rome (Italy)

Alberto Berardi, MD

alberto.berardi@alice.it

Augusto Mosca, MD

moscaugusto@gmail.com

via Tuscolana, 2, 00044 Frascati-RM (Italy) 